\title{
UK dentists urged to see children by age one
}

Claire Stevens (pictured) urged delegates at the British Dental Conference and Exhibition in May to support the British Society of Paediatric Dentistry's (BSPD's) campaign to make 'Dental Check by One' the norm for all children in the UK.

Dr Stevens, a Consultant in Paediatric Dentistry and Vice-President of BSPD, said that only $19 \%$ of children under two saw a dentist in the last year. She asked her audience of around 1,000 delegates, many of them young dentists, to try and see four additional children under two in the coming year. If all the 22,000 dentists with a contract saw four more under twos, then together they could bring down the number of general anaesthetics for dental extractions.

'This is my rallying cry', said Dr Stevens, 'asking you to join me in making the Dental Check by One a reality. Please think how you can make a difference. We need to be innovative and we all need to be working together'

A Dental Check by One is recommended in the Commissioning Guidelines for paediatric dentistry, compiled under the Chairmanship of Stephen Fayle, but still awaiting publication, and was one of the outcomes of the BSPD stakeholders meeting a year ago when all those present committed to support the campaign.

Collaborative working is very much on BSPD's agenda, Claire told her audience, and she went on to describe the work being undertaken in Manchester where she is Chair of the Managed Clinical Network

\section{Oral Reconstruction Foundation Research Award}

The newly relaunched Oral Reconstruction Foundation (former CAMLOG Foundation) has announced the continuation of its renowned Research Award. The Research Award is presented every two years and is open to all young, talented scientists/ researchers and dedicated professionals from universities, hospitals and practices.

The expected scientific papers must be published or accepted for publication in English in a peer-reviewed journal. They must address one of these topics in implant dentistry, oral reconstruction or related areas:

- Diagnostics and planning

- Hard- and soft-tissue management

- Sustainability of implant-supported prosthetics

- Physiological and pathophysiological aspects

- Advances in digital procedures.

The winner of the Oral Reconstruction Foundation Research Award 2016/2017 will have the opportunity to present his/ her work to a wider audience on the occasion of the Oral Reconstruction Global Symposium which takes place in Rotterdam, Netherlands, 26-28 April 2018. Furthermore, the authors of the three best contributions will receive cash prizes ( $€ 10,000, € 6,000$ and $€ 4,000$ respectively).

The entry conditions and the mandatory registration form can be downloaded from www.orfoundation.org/awards. The registration deadline is 30 November 2017.
(MCN) for paediatric dentistry. Local GDPs had taken the lead, she said, in trying to create a network so that all children could get dental care.

Not all dentists wanted to treat children, she said, and she understood this, but she recommended that parents should be signposted to practices where families are welcome. Most children's dentistry is carried out in general practice, and it was important that everyone treating children carried out the same evidence-based treatments.

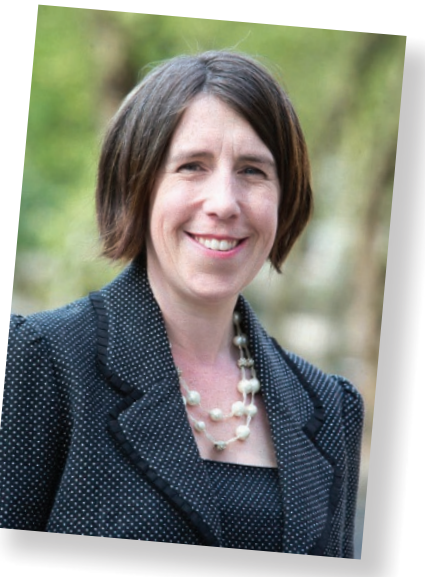

Dr Stevens also advocated the use of Hall crowns for the treatment of decayed primary teeth. The Hall crown technique was developed by a GDP in Scotland and research has shown it to be a superior approach to managing decay compared to conventional restorations and was well tolerated by patients because local anaesthetics weren't usually needed.

Dr Stevens' presentation, which opened the conference, was very well received by delegates and attracted a lot of questions on a wide range of issues relating to children's oral health.

\section{BOS launches new resource for National Smile Month}

The British Orthodontic Society (BOS) has launched a new online resource: 'The BOS Guide: Better teeth for life'. It highlights the positive impact that orthodontic treatment can have on both oral health and emotional wellbeing and provides practical tips on a patient's role in achieving excellent results.

This new guide is supported by recent research

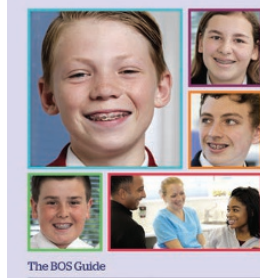

Better teeth for life undertaken at the University of Sheffield School of Clinical Dentistry which found orthodontic treatment before the aged of 18 improves oral health-related quality of life (OHRQoL), with most reported improvement around emotional and social well-being. ${ }^{1}$

The guide links in with World Oral Health Day which has been created by the World Federation of Orthodontists and both initiatives coincide with the UK's National Smile Month run annually by the Oral Health Foundation.

Alison Murray, President of the British Orthodontic Society, said: 'This new BOS Guide demonstrates how life-enhancing orthodontic treatment can be. We know that patients in braces are encouraged to keep their mouths really clean and there is evidence that once treatment has been completed, patients continue to look after their teeth.

Orthodontics should be the start of a lifetime of excellent dental health'

The guide can be accessed via: http://www.bos.org.uk/

Public-Patients/News-Publications/Public-Patients-News.

1. Javidi $\mathrm{H}$, Vettore $\mathrm{M}$, Benson $\mathrm{PE}$. Does orthodontic treatment before the age of 18 years improve oral health-related quality of life? A systematic review and meta-analysis. Am J Orthod Dentofacial Orthop 2017; 151: 644-655. 